\title{
Sustentabilidade em Empresas de Tecnologia da Informação
}

\author{
Marcelo Benites Gonçalves ${ }^{1}$, Orlando Zotelli Júnior ${ }^{1}$, Débora M. Barroso Paiva ${ }^{1}$ \\ ${ }^{1}$ Faculdade de Computação - Universidade Federal de Mato Grosso do Sul (UFMS) \\ Caixa Postal 549 - 79.070-900 - Campo Grande - MS - Brazil \\ \{marcelo_benites_goncalves, orlando007\}@hotmail.com, debora@facom.ufms.br
}

\begin{abstract}
Resumo. A necessidade de produzir bens de consumo de forma sustentável tem sido observada atualmente por empresários e clientes e tem sido amplamente explorada pelos meios de comunicação. Este artigo tem como principal objetivo apresentar os resultados de um levantamento inédito sobre as medidas de sustentabilidade praticadas atualmente em empresas de Tecnologia da Informação (TI) instaladas no Brasil. Buscou-se, com isso, apresentar um panorama sobre a adoção de práticas sustentáveis nos processos de desenvolvimento de software das organizações, oportunidades de melhoria e desafios para os próximos anos. Para divulgar a questão ambiental na área de Tecnologia da Informação foi criado um portal web de cunho informativo para os pesquisadores e interessados no tema.
\end{abstract}

\section{Introdução}

Entre os mais importantes desafios que emergem dos setores produtivos, está a responsabilidade ambiental. Produzir sem degradar o meio ambiente e manter a competitividade é uma tarefa muito distante da trivialidade. O próprio conceito de sustentabilidade causa discussão, pois a relação entre as atividades das organizações e a capacidade da biosfera de absorver os efeitos negativos dessas atividades ainda é obscura.

É sob esse novo paradigma de produção que a área de TI também se vê inserida e, como grande colaboradora no consumo de energia e recursos naturais, os seus processos também devem ser examinados, melhorados e adaptados no intuito de gerar produtos e fornecer serviços de forma ecologicamente correta. Neste contexto, a TI Verde pode ser entendida como uma estratégia corporativa que almeja a preservação ambiental e traz consigo grandes vantagens não só para o meio ambiente como também para as próprias organizações que a integram em seus projetos.

Desta forma, este artigo está contextualizado no tema proposto para o SBSI 2010 que se refere a "Desafios para o Desenvolvimento Sustentável Apoiado em TI". De forma geral, o artigo apresenta os resultados de um projeto de pesquisa que teve como principal objetivo identificar se empresas de TI estão considerando a sustentabilidade em seus processos de produção. Sabe-se atualmente que há pesquisas interessadas em integrar a sustentabilidade a diferentes setores, no entanto, não há resultados divulgados na literatura científica sobre os mecanismos utilizados pelas empresas de TI nesse sentido. Buscou-se tratar o tema de uma forma exploratória e colaborativa, submetendo questionários à empresas de TI com o objetivo de conhecer as medidas de sustentabilidade que empregam. Os resultados obtidos, de forma geral, indicam que há grande interesse do setor em termos de sustentabilidade e, por outro lado, falta conhecimento (pesquisas, normas, documentos) no assunto. Com a realização deste trabalho foi possível identificar 
áreas que demandam a realização de pesquisas nos próximos anos no contexto de TI e sustentabilidade.

Este artigo está organizado da seguinte forma: a seção 2 apresenta uma revisão da literatura sobre sustentabilidade e TI. A seção 3 apresenta a discussão sobre o questionário submetido às empresas de TI. A seção 4 apresenta o Portal do Software Verde, que é uma consequência de resultados da pesquisa, e a seção 5 se refere às conclusões do trabalho.

\section{Visão Geral sobre Sustentabilidade}

Ao longo de 40 anos, a palavra sustentabilidade foi debatida e difundida por pesquisadores. Uma referência importante, considerada marco zero por vários cientistas, foi o livro intitulado Primavera Silenciosa, que tinha como principal objetivo a denúncia do uso do Dicloro-Difenil-Tricloroetano (DDT) na agricultura e como este pesticida afetava o nosso organismo [Carson 1968]. Ao longo de décadas, a preocupação com o meio ambiente aumentou e novas práticas surgiram, agregando pontos favoráveis ao equilíbrio do planeta. Manter esse estado de equilíbrio entre os recursos naturais, espécies animais, vegetais e a poluição pode implicar em um uso condicional dos recursos não-renováveis. Manter o estado de equilíbrio é um dos objetivos do desenvolvimento sustentável.

Autora de vários livros ligados ao tema, Laville [Laville 2009] apresenta uma forma racional e matemática do desenvolvimento sustentável. Como indicado na Figura 1, o desenvolvimento sustentável é quase sempre representado sob a forma de um triângulo que evidencia os três objetivos perseguidos: econômico (criação de riqueza para todos através de modos de produção e de consumo duráveis), ecológico (conservação e gestão de recursos) e social (igualdade e participação de todos os grupos sociais). A ideia é que os três objetivos sejam atingidos simultaneamente, apesar da dificuldade evidenciada pela própria forma triangular: a busca por um objetivo normalmente se faz em detrimento dos outros dois.

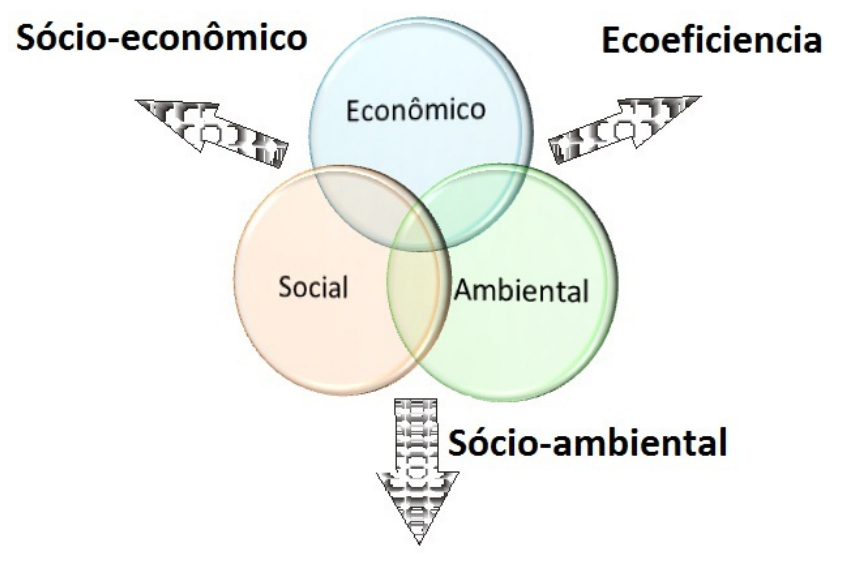

Figura 1. Os três objetivos do desenvolvimento sustentável [Laville 2009]

A inovação tecnológica é o elemento gerador de mudanças que não se relaciona apenas a questões de ordem técnico-científica, mas apresenta também dimensões de ordem política, econômica e sócio-cultural [Cavalcanti 1994]. Na subseção 2.1 será discutido o tema da sustentabilidade na área de TI com o intuito de apresentar trabalhos que 
indicam como inovação tecnológica e sustentabilidade podem ser considerados de forma conjunta.

\subsection{TI e as iniciativas em sustentabilidade}

A sustentabilidade em TI representa a capacidade da empresa em gerir seus ativos tecnológicos de forma eficiente, mantendo o equilíbrio com a sociedade e o meio ambiente. O conceito de TI Verde é amplamente utilizado e pode ser definido como o estudo e a prática de projeto, manufatura, uso e descarte de computadores e subsistemas eficientemente com impacto mínimo no ambiente (ou nenhum impacto) [Gupta 2010].

Quando um executivo de TI atua de forma consistente em ações de responsabilidade social e projetos ligados ao meio ambiente, sua empresa passa a ser percebida com mais valor pelo mercado e pela sociedade. Segundo levantamento feito pela empresa líder de Tecnologia da Informação, International Data Corporation (IDC), $80 \%$ dos executivos brasileiros dizem que iniciativas de TI Verde estão crescendo em importância nas suas organizações e 43\% ressaltam que, na hora de escolher um fornecedor, já prestam atenção nas suas ações de preservação ambiental [Info Exame 2009].

Fabricantes de computadores e de outros dispositivos eletrônicos portáteis como PDAs, celulares, smartphones e leitores de mp3 também estão se conscientizando a respeito da minimização dos impactos ambientais. Entre as tecnologias cada vez mais adotadas estão as soldas sem chumbo e placas de circuito impresso desprovidas de bromo, o que as torna menos tóxicas quando descartadas.

De acordo com Macagnani [Macagnani 2009], nos últimos anos as empresas têm adotado a virtualização como uma das alternativas para diminuição de custos. O conceito de máquina virtual não é novo, suas origens remetem ao início da história dos computadores, no final dos anos de 1950 e início de 1960. As máquinas virtuais foram originalmente desenvolvidas para centralizar os sistemas de computador utilizados no ambiente VM/370 da IBM. Naquele sistema, cada máquina virtual simula uma réplica física da máquina real e os usuários têm a ilusão de que o sistema está disponível para seu uso exclusivo. Assim, a utilização de máquinas virtuais está se tornando uma alternativa para vários sistemas de computação, pelas vantagens em custos e portabilidade, inclusive em sistemas de segurança.

De forma semelhante, a virtualização de desktops utiliza servidores terminais, em que cada usuário conectado possui a sua sessão dentro de um mesmo sistema operacional. A virtualização de desktops é uma das próximas grandes tendências no ramo da virtualização. É uma alternativa amigável em relação ao uso de servidores, pois garante a total compatibilidade das aplicações, uma maior familiaridade de uso para os usuários e o isolamento total dos ambientes [Miller and Pegah 2007, Tulloch 2009].

Por outro lado, nota-se que as principais medidas colocadas em prática na área de TI que contribuem com o meio ambiente estão ligadas à economia de energia elétrica e redução de custos com equipamentos. Uma dificuldade está em como obter conhecimento para liderar a área. Não existe ainda um currículo padrão para as melhores práticas de TI Verde. Isso significa que os profissionais precisam propor alternativas e descobrir novas abordagens ao mesmo tempo em que são cobrados por fornecer produtos e serviços ecologicamente corretos. 


\section{Sustentabilidade em Empresas de TI: Resultados de um Survey}

O principal objetivo do survey realizado no contexto deste trabalho foi a obtenção de informações sobre quais medidas de sustentabilidade são colocadas em prática pelas empresas de TI que atuam no Brasil. Foram selecionadas as empresas brasileiras ${ }^{1}$ que já possuem algum nível de maturidade no modelo CMMI (Capability Maturity Model) [Software Engineering Institute 2009] ou no modelo MR MPS.BR (Melhoria de Processos do Software Brasileiro) [SOFTEX 2009], de forma a avaliar núcleos de desenvolvimento que já possuam uma estrutura de gestão de projetos organizada.

Foi enviado um email a 187 empresas com avaliações CMMI ou MR MPS.BR bem sucedidas. Ao todo, foram obtidas respostas de 30 empresas e a identidade destas foi preservada. A quantidade de empresas que respondeu ao questionário de acordo com seus níveis de maturidade pode ser observado na Tabela 1.

Tabela 1. Empresas que responderam ao questionário de acordo com seus níveis de maturidade

\begin{tabular}{|l||l||l||l||l||l||l||l||l||l||l||l|}
\hline & 2 & 3 & 4 & 5 & G & F & E & D & C & B & A \\
\hline CMMI & 4 & 4 & 0 & 4 & - & - & - & - & - & - & - \\
\hline MPS-BR & - & - & - & - & 9 & 7 & 2 & 0 & 0 & 0 & 0 \\
\hline
\end{tabular}

\subsection{Questionário}

Na elaboração do questionário consideraram-se problemas críticos e fatores de sucesso em termos de sustentabilidade na área de TI. O conhecimento necessário para elaboração das questões foi obtido a partir de revisão bibliográfica. O questionário foi dividido em duas partes, conforme apresentado na Figura 2. A parte II foi respondida apenas por empresas que já possuem programas de sustentabilidade em TI. Considerando as $30 \mathrm{em}-$ presas que enviaram respostas para o questionário, 3 empresas não responderam a parte II.

\subsubsection{Primeira parte do questinário}

O objetivo desta fase foi identificar se as empresas consideram algum elemento ligado à sustentabilidade em seus processos. Assim, a questão 1 analisa um dos fatores mais críticos de sustentabilidade nas áreas de TI - o controle de energia. Além de se tratar de um problema ambiental amplamente estabelecido, e por isso mais observado, o controle energético é uma das medidas que traz um retorno financeiro facilmente observável.

A questão 2 trata da virtualização de servidores e está diretamente ligada à economia de energia e de investimentos em hardware. Por ser uma atividade também já estabelecida antes do próprio conceito de TI Verde, muitas empresas já adotam essa prática, mesmo sem ter uma preocupação direta com o desenvolvimento sustentável. A redução de custos pode ser vista muitas vezes como um incentivo que precede a preocupação ambiental.

\footnotetext{
${ }^{1}$ Inclui empresas genuinamente brasileiras e também empresas multinacionais com núcleos de desenvolvimento estabelecidos em território brasileiro.
} 


\begin{tabular}{|c|c|}
\hline PARTE I & PARTE II \\
\hline QUESTÕES PARA TODAS AS EMPRESAS & $\begin{array}{c}\text { QUESTÕES PARA AS EMPRESAS QUE TÊM } \\
\text { PROGRAMAS ESPECÍFICOS DE } \\
\text { SUSTENTABILIDADE EM TI }\end{array}$ \\
\hline 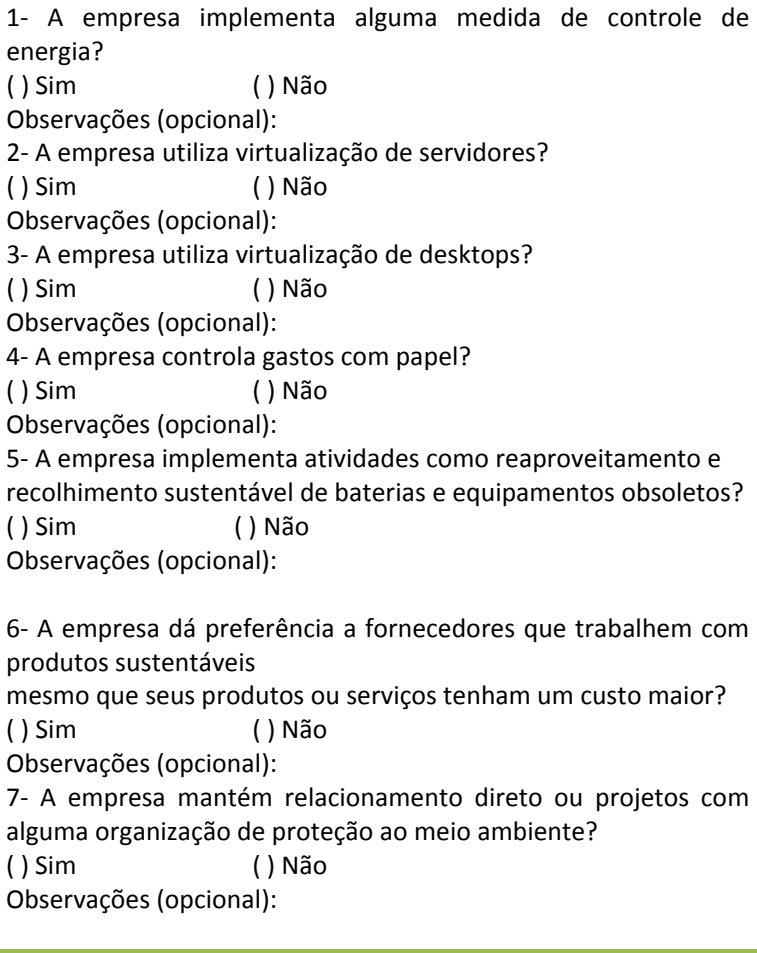 & 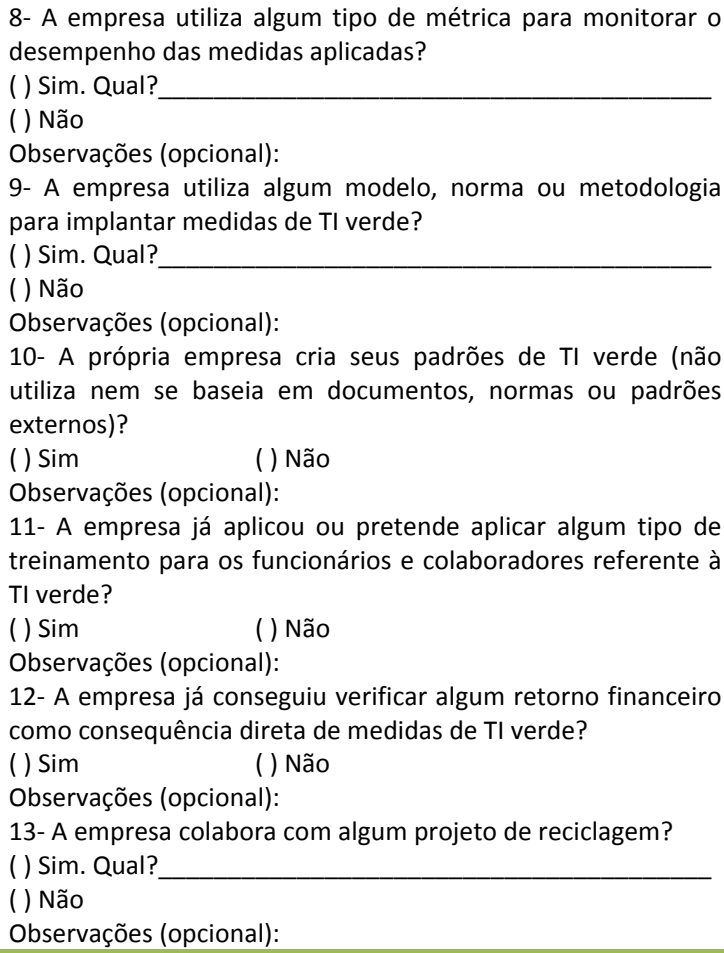 \\
\hline
\end{tabular}

Figura 2. Questionário enviado às empresas

A questão 3, sobre virtualização de desktops, aborda uma prática nova no mercado de TI. A intenção é verificar o nível de atualização das empresas com as tecnologias e soluções sustentáveis emergentes. O objetivo de economia também pode ficar à frente da sustentabilidade nesta questão mas, por demandar investimentos em migração de tecnologias, a relação entre investimento e economia pode pesar tanto positivamente quanto negativamente nesta questão.

As questões 4 e 5 envolvem impactos ambientais que têm medidas de combate predominantemente culturais cujo fator crítico de sucesso é a mudança no comportamento e forma de trabalho dos membros das organizações. Ambas as questões estão ligadas a atitudes de mudanças comportamentais dos membros das organizações e a questão 5 também está relacionada ao item seguinte sobre iniciativas e parcerias, pois o descarte de certos equipamentos só é possível estabelecendo parcerias com outras organizações.

Iniciativas em favor do meio ambiente podem trazer custos, o que pode ser visto como um investimento em responsabilidade sócio-ambiental pela empresa ou como uma barreira que inibe sua aplicação. A questão 6 considera este argumento e investiga se possíveis custos são um fator limitante neste contexto.

Dar preferência a produtos ecologicamente corretos mesmo que possam ter um 
custo maior mostra um compromisso da empresa com o desenvolvimento sustentável. Esse fator indica maturidade ao encarar o desenvolvimento sustentável não somente como uma ferramenta de auto promoção, mas como parte integrante e necessária em seus processos de produção.

A questão 7, sobre projetos e parcerias, verifica se as empresas buscam, de alguma forma, experiências, conhecimento ou a união de esforços para realizar ações de preservação e sustentabilidade.

\subsubsection{Segunda parte do questionário}

O foco da segunda parte do questionário foi as empresas que já possuem algum programa específico de sustentabilidade em TI. O propósito foi colher dados sobre como essas empresas instituem e organizam seus processos de gestão sustentável e qual o êxito que têm obtido com seus programas.

A questão 8 verifica se as empresas utilizam alguma métrica para monitorar o desempenho de suas medidas de sustentabilidade. É importante verificar quais são os aspectos mensuráveis considerados por essas empresas em seus programas de gestão sustentável.

As questões 9 e 10 têm a intenção de verificar quais estudos e conhecimentos são utilizados pelas empresas em seus programas de sustentabilidade, pois não há nenhuma norma obrigatória ou lei de responsabilidade a ser seguida. A utilização de modelos de terceiros ou criação de modelos próprios sinaliza uma preocupação positiva com a formalização e padronização de processos para a gestão sustentável. A questão 11 verifica se as empresas ministram treinamento, dentro de seus programas de TI Verde.

A questão 12 foi tratada na segunda parte do questionário pela possibilidade de ruído nos dados. Sem programas específicos, a tarefa de verificar lucros a partir de medidas de TI Verde pode ser extremamente imprecisa e trazer informações incorretas para o survey. Desta forma, somente os lucros em empresas que já possuem programas específicos foram verificados.

A constatação de retornos financeiros é um elemento importante e ao mesmo tempo complexo. O desenvolvimento sustentável pode englobar diversas atividades em momentos e setores diferentes de uma empresa dentro de um mesmo projeto, e essa verificação de lucratividade é uma tarefa que ainda demanda muitos estudos.

Processos de reciclagem podem se instalar em vários momentos no conjunto de processos de produção. A questão 13 tenta verificar iniciativas de reciclagem diretamente ligadas ou geradas a partir modelos de gestão que incluam o desenvolvimento sustentável entre seus objetivos.

\subsection{Análise de resultados}

A primeira atividade realizada na etapa de análise dos resultados foi a definição de níveis de maturidade em desenvolvimento sustentável nos quais as empresas poderão estar enquadradas. Uma breve descrição dos níveis de maturidade é apresentada a seguir:

- Nível 0: empresas sem qualquer iniciativa em sustentabilidade ou que possuem iniciativas muito elementares; 
- Nível 1: empresas que já possuem alguma preocupação com sustentabilidade mas ainda não direcionam esforços e investimentos significativos específicos para a integração do desenvolvimento sustentável em seus projetos;

- Nível 2: empresas que têm a sustentabilidade como um elemento de melhoria contínua, direcionando esforços e planejamentos para integração do desenvolvimento sustentável em seus processos.

A distribuição das empresas nos níveis propostos considerou uma avaliação das respostas obtidas com o questionário. As questões que compuseram o questionário foram distribuídas de acordo com a seguinte ordem lógica:

- Econômico: medidas que têm como principal característica o retorno financeiro (questões 1, 2, 4 e 12);

- Medidas Básicas: incluem atividades simples e que não demandam investimentos ou direcionamento de esforços (questões 3, 11 e 13);

- Medidas Específicas: englobam medidas específicas em sustentabilidade, que demandam investimentos e esforços específicos (questões 5, 6, 7, 8, 10);

- Medidas Integradas: caracterizam a mobilização da empresa em direção à integração do desenvolvimento sustentável com seu processo de software (questão 9).

Pesos foram atribuídos às questões e cada nível recebeu uma faixa de valor para somatório, conforme ilustrado na Figura 3. Desta forma, para encontrar o nível de uma empresa, foi realizado um somatório de cada resposta positiva devidamente multiplicada pelo peso correspondente à questão. Por exemplo, uma empresa que respondeu positivamente às questões 3 e 11 terá seu somatório final com o valor 4 ( (1 resposta positiva * peso $2)+(1$ resposta positiva * peso 2$))$ e estará no Nível 0. A motivação para a atribuição dos pesos foi diferenciar ações mais simples de ações mais complexas em implantação de sustentabilidade. Por exemplo, a ação descrita na questão 1 ("A empresa implementa alguma medida de controle de energia?") recebeu peso 1 por ser muito mais simples que a ação descrita na questão 9 ("A empresa utiliza algum modelo, norma ou metodologia para implantar medidas de TI verde?"), que recebeu peso 6.

Do total de 30 empresas que responderam ao questionário, 5 ficaram no Nível 0, 17 no Nível 1 e 8 no Nível 2. Com a maior fatia enquadrada no Nível 1 (Figura 4), foi verificado que grande parte das empresas já tem uma preocupação com a sustentabilidade em seus projetos, implementando algumas iniciativas em sustentabilidade. Porém ainda não direcionam esforços para institucionalizar o desenvolvimento sustentável em seus processos de produção. Há uma tendência para que isso ocorra, mas a própria complexidade desta tarefa faz com que ela evolua lentamente.

\subsection{Análise Individual das Iniciativas}

Conforme apresentado nas Figuras 5 e 6, nota-se que, a preocupação atual das áreas de TI com o meio ambiente tem um foco mais fortemente voltado para aspectos econômicos do que uma real preocupação com o futuro do planeta ou até mesmo com a imagem de responsabilidade sócio-ambiental da empresa. Práticas como dar preferência à aquisição de produtos e serviços ecologicamente corretos não recebem muita atenção das empresas pesquisadas por ser um elemento gerador de despesas em potencial e que dificilmente é exposto como um diferencial de desenvolvimento sustentável em seus produtos. 


\section{Distribuição das Questões}

\begin{tabular}{|c|c|c|}
\hline Caráter Predominante & Peso & Questões \\
\hline Econômico & 1 & $1-2-4-12$ \\
\hline Medidas Básicas & 2 & $3-11-13$ \\
\hline Medidas Específicas & 4 & $5-6-7-8-10$ \\
\hline Medidas Integradas & 6 & 9 \\
\hline \multicolumn{3}{|c|}{ Distribuição nos Níveis } \\
\hline Nível 0 & \multicolumn{2}{|c|}{ Somatório 0 a 5} \\
\hline Nível 1 & \multicolumn{2}{|c|}{ Somatório 5 a 20} \\
\hline Nível 2 & \multicolumn{2}{|c|}{ Somatório acima de 20} \\
\hline
\end{tabular}

Figura 3. Esquema lógico de distribuição das questões com seus respectivos pesos

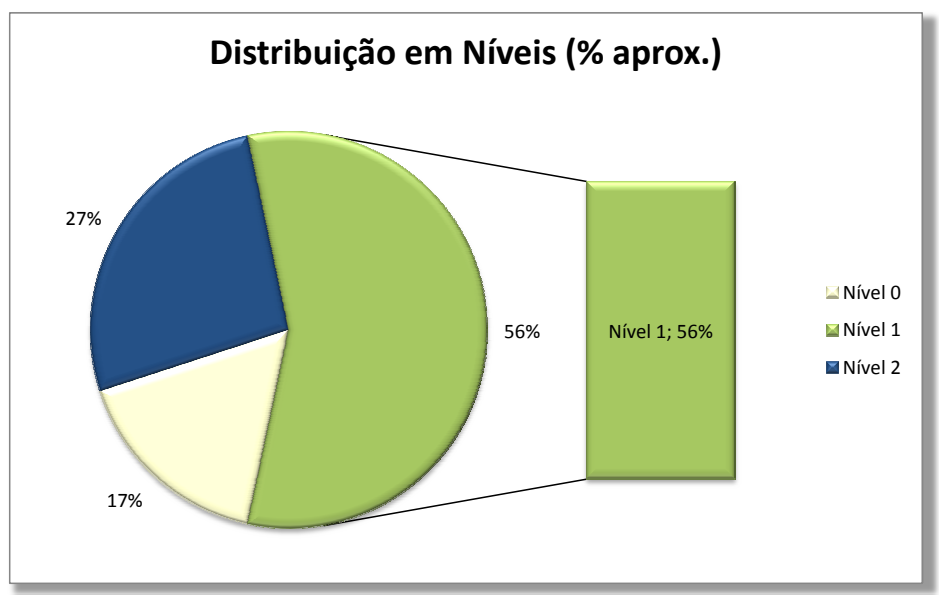

Figura 4. Distribuição das empresas conforme os níveis alcançados em suas respostas ao questionário

A boa participação das empresas na questão sobre treinamentos indica, no mínimo, uma preocupação em integrar os membros da empresa com os objetivos de sustentabilidade da mesma. Outro fator observado foi a falta de padrões, modelos ou métricas específicas para o desenvolvimento sustentável nas áreas de desenvolvimento de software. A grande maioria das empresas alegou não adotar modelos de TI Verde mesmo tendo programas específicos para sustentabilidade no setor. Algumas alegaram não encontrar modelos específicos ou aplicáveis que sejam compatíveis com seus objetivos e processos de produção pré-existentes.

Muitas empresas alegaram não ter observado lucros decorrentes de práticas de TI Verde. Isso também pode ser conseqüiência de uma falta de padrões, métricas ou modelos de monitoramento e avaliação de retornos financeiros para as medidas de sustentabilidade adotadas, pois muitas práticas podem gerar retornos indiretos ou em longo prazo de difícil observação. Por exemplo, a virtualização de desktops pode gerar uma economia de energia em refrigeração do ambiente de trabalho. 


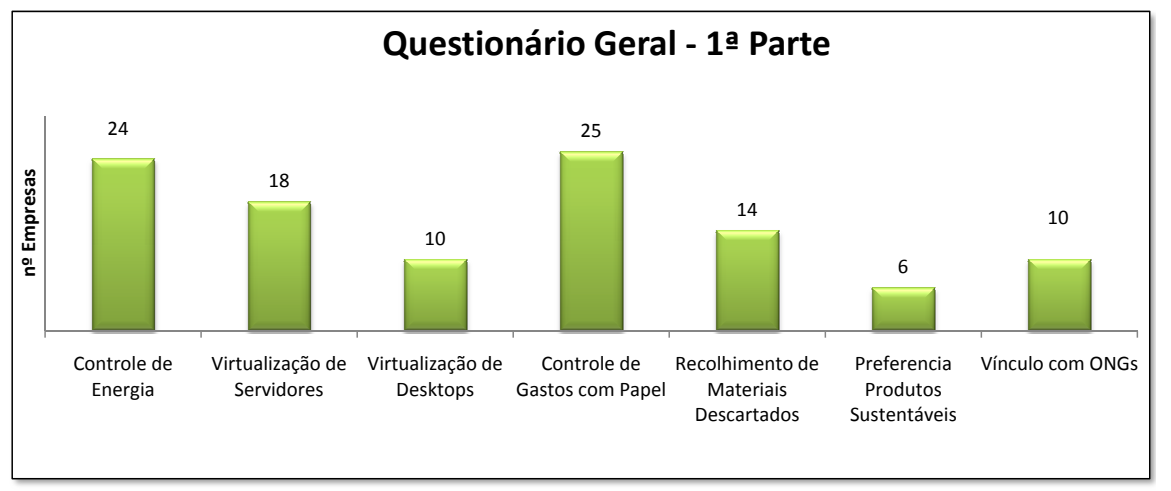

Figura 5. Quantidade de respostas positivas às questões referentes a primeira parte do questionário proposto

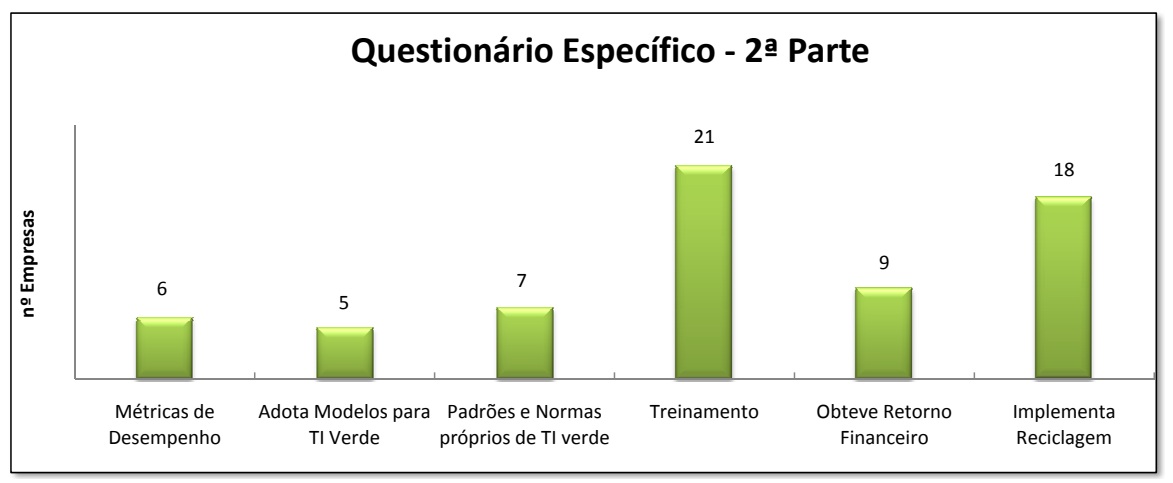

Figura 6. Quantidade de respostas positivas às questões referentes a segunda parte do questionário proposto

Como resultado deste trabalho, observou-se que há demanda por pesquisas relacionadas à integração entre sustentabilidade e processos de TI. Mais especificamente, foi possível notar que futuras linhas de pesquisa deverão contemplar:

1. Modelagem e elaboração de material didático que auxilie as empresas na tarefa de conscientização e treinamento dos funcionários em termos de processos de TI e sustentabilidade;

2. Criação de mecanismos de divulgação de informações sobre o tema, incluindo alternativas como portais web, arquivos multimídia, cartilhas, etc;

3. Elaboração de documentos, modelos e normas técnicas sobre o tema que possam ser adotados em organizações do setor de TI;

4. Elaboração de modelos que ajudem a avaliar e medir os custos e benefícios obtidos a partir da aplicação de medidas de sustentabilidade no setor de TI.

Neste trabalho, buscou-se explorar o item 2 elaborando o "Portal do Software Verde", conforme apresentado na próxima seção. Além disso, buscou-se explorar o item 3 dando início à formulação de um documento técnico que sirva como um subsídio para a implantação de práticas de sustentabilidade em organizações de TI. O padrão proposto foi descrito por Gonçalves et al [Gonçalves et al. 2010]. De forma geral, para a elaboração do padrão foi realizada uma adaptação do PMBOK [Project Management Institute (PMI) 2004] sugerindo processos de gestão sustentável em projetos de desenvolvimento de software. Propõe-se, desta forma, um amadurecimento 
progressivo das empresas de desenvolvimento de software, fomentando melhorias e iniciativas como avaliação de níveis de maturidade em gestão sustentável de projetos de desenvolvimento de software.

\section{Portal do Software Verde}

Para divulgar o documento técnico desenvolvido e promover ações de sustentabilidade nas áreas de TI (com enfoque no setor de desenvolvimento de software), foi desenvolvido um portal informativo que reúne um material do trabalho desenvolvido, orientações sobre ações de sustentabilidade, publicações relevantes, notícias relacionadas à TI Verde e alertas para a comunidade da área de TI sobre a necessidade de apoio às questões ambientais. O portal está disponível em http://tiverde.50webs.com/.

Este portal propõe a reunião de dados úteis para o desenvolvimento sustentável no contexto da TI. O conteúdo inicial do portal é apenas um ponto de partida, de forma que sua própria concepção já agrega a característica de extensibilidade ${ }^{2}$, permitindo a adição de novos conteúdos e ferramentas quando necessário.

Outras características importantes consideradas na elaboração do portal foram:

- Portabilidade: apresentação de conteúdo entre diferentes navegadores (testes realizados com Firefox, IE).

- Estética e Design minimalista [Jakob Nielsen 2007]: apresentação dos elementos relevantes do conteúdo, não utilizar informações desnecessárias no portal. Design simples e agradável para navegação.

O portal é basicamente uma página em HTML 1.1 (HyperText Markup Language) sem utilizar recursos sofisticados de linguagens, já que sua proposta inicial é ser uma ferramenta informativa básica para a divulgação de conteúdo. Implementa alguns recursos visuais em Cascading Style Sheets (CSS) ${ }^{3}$ e dispõe de uma organização de conteúdo que proporciona uma navegação simples e uma experiência visual agradável.

A página inicial do portal (Figura 7) apresenta as informações básicas sobre o conteúdo do portal e disponibiliza um menu principal para localização de informações. Ao navegar por algum item do menu principal que tenha sub-itens, o usuário terá uma navegação em abas destes sub-itens contida na página principal como indicado na Figura 8.

\section{Conclusões}

O relacionamento das empresas brasileiras de desenvolvimento de software com a TI Verde é um assunto ainda pouco explorado. As tendências de mercado indicam um futuro provável onde será impossível conceber a ideia de qualidade de produto desvinculada do conceito de responsabilidade sócio-ambiental.

A principal dificuldade enfrentada durante o desenvolvimento do survey foi no processo de obtenção de respostas ao questionário por parte das empresas. Algumas organizações de grande porte se recusaram a responder alegando que os dados solicitados

\footnotetext{
${ }^{2}$ Do Inglês: extendability, como capacidade de agregar novos elementos e conteúdos.

${ }^{3}$ Uma linguagem de composição de estilos utilizada para definir elementos de apresentação de documentos produzidos em linguagens como o HTML com dados estáticos.
} 


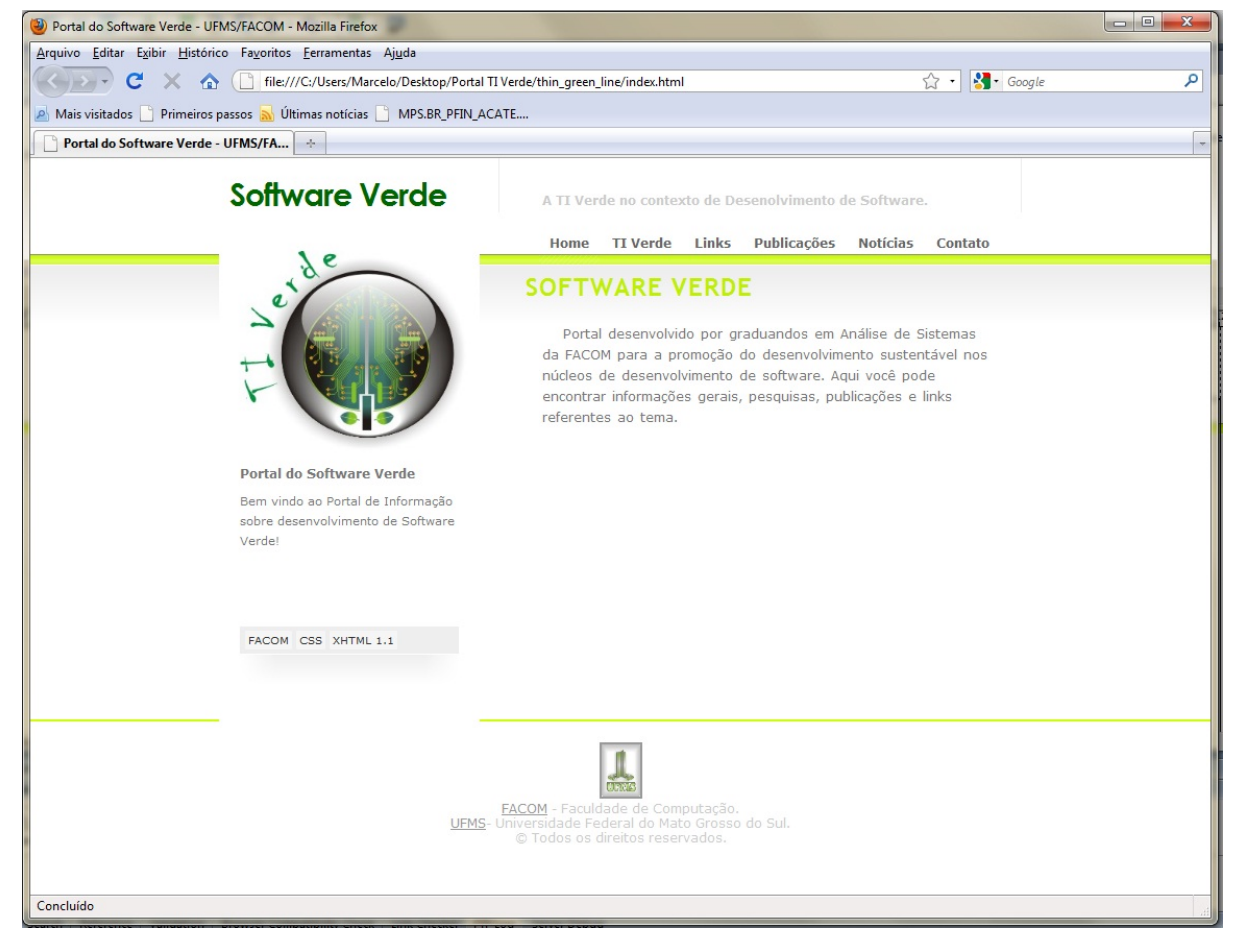

Figura 7. Página inicial do portal.

poderiam comprometer estratégias corporativas e informações sigilosas. Muitas empresas de pequeno porte não responderam aos contatos realizados.

Considera-se que a principal contribuição deste trabalho foi a proposta de discussão do tema sob uma perspectiva científica com o intuito de divulgar e fazer um primeiro levantamento sobre as iniciativas das empresas de TI que atuam no Brasil em relação à sustentabilidade. Trabalhos futuros referem-e a realização de novos surveys considerando outros elementos, tais como ferramentas utilizadas pelas empresas e tecnologias disponíveis para promover a sustentabilidade no setor de TI. Além disso, observa-se que é urgente a realização de novas pesquisas em termos de aplicativos e hardware que valorizem a sustentabilidade. Por exemplo, a computação em nuvens (cloud computing) [Buyya et al. 2009] oferece grande potencial para diminuição de lixo eletrônico nas empresas, porém, poucos aplicativos de software contemplam atualmente esta tendência.

\section{Referências}

Buyya, R., Yeo, C. S., Venugopal, S., Broberg, J., and Brandic, I. (2009). Cloud computing and emerging IT platforms: vision, hype, and reality for delivering computing as the 5th utility. Future Gener. Comput. Syst., 25(6):599-616.

Carson, R. (1968). Silent Spring. Houghton Mifflin Harcourt Publishing Company.

Cavalcanti, C. (1994). Desenvolvimento e Natureza: Estudo para uma sociedade sutentável. INPSO/FUNDAJ, Instituto de Pesquisas Sociais, Fundação Joaquim Nabuco, Ministério de Educação, Governo Federal.

Gonçalves, M. B., Júnior, O. Z., and Paiva, D. M. B. (2010). Incluindo o fator de sustentabilidade no gerenciamento de projetos de software. Submetido ao XXIV Simpósio Brasileiro de Engenharia de Software (SBES). 


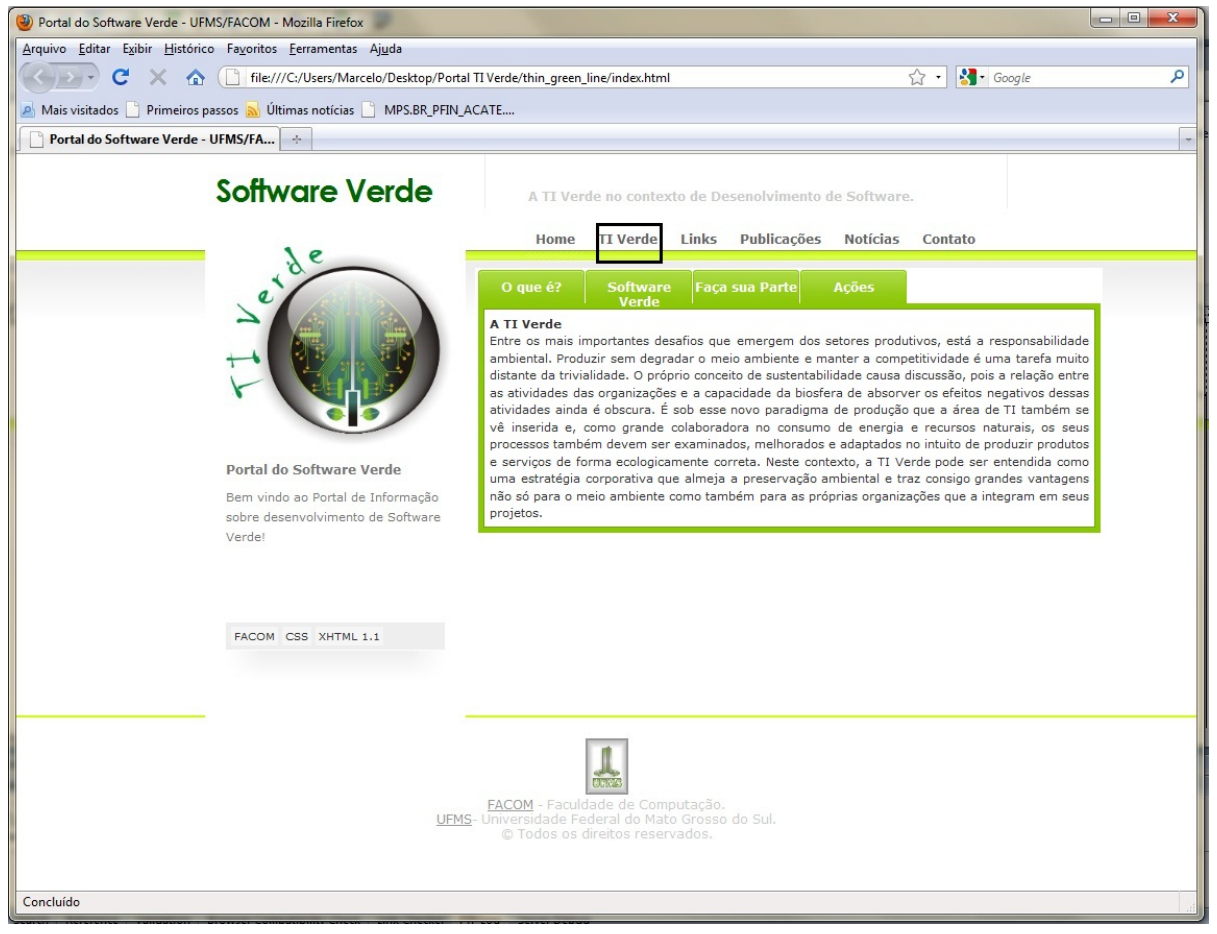

Figura 8. Sub-menu com informações sobre TI Verde do portal.

Gupta, S. (2010). Computing with green responsibility. In ICWET'10: Proceedings of the International Conference and Workshop on Emerging Trends in Technology, pages 234-236, New York, NY, USA. ACM.

Info Exame (2009). GaDGETS. Agosto.

Jakob Nielsen, H. L. (2007). Projetando Websites com Usabilidade. Elsevier.

Laville, E. (2009). A Empresa Verde. Editora Ote.

Macagnani, B. (2009). Virtualização de desktops, uma solução econômica. http: // under-linux.org/.

Miller, K. and Pegah, M. (2007). Virtualization: virtually at the desktop. In SIGUCCS '07: Proceedings of the 35th annual ACM SIGUCCS conference on User services, pages 255-260, New York, NY, USA. ACM.

Project Management Institute (PMI) (2004). Um Guia do Conjunto de Conhecimentos em Gerenciamento de Projetos - Guia PMBOK.

SOFTEX (2009). Mps.br - melhoria de processos do software brasileiro. http: / / www . softex.br/mpsBr/.

Software Engineering Institute (2009). CMMI - Capability Maturity Model - version 1.2. http://www.sei.cmu.edu/cmmi/index.cfm.

Tulloch, M. (2009). Understanding Microsoft Virtualization Solutions from the Desktop to the Datacenter. Microsoft Press. 